Pimozide (a diphenylbutylpiperidine) or haloperidol (a butyrophenone) are obvious candidates, and in neither cases has blood dyscrasia been reported as a problem. Regular blood samples over the first few weeks of treatment with any such agent would seem to be prudent.

I wish them well with the case, and cannot help thinking of the well-publicised problem of neutropaenia with clozapine, the exact mechanism of which has so far eluded the manufacturers. If there were to be a surface receptor action shared by all antipsychotic drugs and possessed in large measure by clozapine, which is unrelated to dopamine receptor blockade, then the implications for a new approach to antipsychotic drug design could be intriguing.

Argyll \& Bute Hospital

ANGUS MACKay

Lochgilphead

Argyll PA31 8LD

\section{Philic disorders: are there such things as positive neuroses?}

\section{DEAR Sirs}

This is a brief self-revelatory piece written to put forward an idea and to find out if colleagues have had similar experiences.

I am a male married caucasian psychiatrist in my late 30s. Almost two years ago I developed a "philia" ("an intense, senselessly persistent and disproportionately pleasurable preoccupation with an activity or pursuit"). The disorder had a very acute onset, arising during the course of a televised penalty shoot-out during the 1990 World Cup. My wife insisted my son and I watch the football. Previously antipathetic to soccer, I then developed a lively and pleasurable interest in all things soccerial. This included attendance at most of Stoke City's home matches, Sunday afternoons in front of the TV watching 'The Match', reading When Saturday Comes on train journeys, a trip to Wembley, getting up early on Sundays to help with a kids soccer team etc. etc. For several months I had a tendency to go off to sleep thinking about the game (rather than work I believe this to be a pathognomonic feature of the philic disorder). During my summer holiday I went to a French second division match.

The disorder was intense for the whole season but has gradually improved and become less financially disabling since. Why did it arise? A cardiologist friend believed that my previous antipathy to the game was a subconscious rejection of my workingclass origins. I had in fact a strong family history of chronic active soccerphilia (a father who was a Blackburn Rovers season ticket holder for 30 years). A 10-year-old son who was more than willing to share the interest with me was an important maintaining factor, as was a wife who was tolerant of this aberration. My working life was particularly hectic at the time and a source of temporary escape was most welcome. I wondered if I was alone in having experienced such an acute philia but, on making enquiries, discovered that I was not. The commonest object of an acute philic disorder I have encountered is windsurfing $(\mathrm{n}=2$, a general surgeon and a gynaecologist). Given that this is a post-Freudian pursuit I refrained from interpreting it. I would be interested to know if Bulletin readers have experienced similar disorders. Of particular interest is whether this is a sex-linked or culture bound phenomenon. Also, would selective 5-HT uptake inhibitors reduce its severity? If not, then what is the most helpful therapy? Finally, will Stoke City make it to the final of the Autoglass Trophy and get to Wembley for the first time since 1972 ?

University of Keele

KEN BARRETT 